\title{
Primary Health Care in relation to leprosy in Sri Lanka
}

\author{
D S P SABAPATHY \\ Central Leprosy Clinic, Room 21, OPD General Hospital, Colombo, \\ Sri Lanka
}

Received for publication 17 March 1982

Sri Lanka is an island 23,332 square miles in extent with a population of about 15 million. It has several different races, the majority being Sinhalese (73\%); others are Tamils (19\%), Moors (7\%), Burghers and Eurasians (0.3\%), Malays $(0.3 \%)$ and unspecified $(0.1 \%)$.

The total number of registered cases of leprosy at the end of 1981 was $11,389,29.6 \%$ being lepromatous; prevalence rate is $0.77 \%$; child rate is $6.2 \%$. 617 new cases were registered during 1981.

Primary Health Care (PHC) in Sri Lanka is dependent on Public Health Midwives (PHM - 1 per 3,000 population), Public Health Inspectors (PHI 1 per 30,000 population), and Public Health Nurses (PHN - 1 per 100,000 population), supervised by Medical Officers of Health ( $\mathrm{MOH}-1$ per 200,000 population). Each $\mathrm{MOH}$ has several PHIs under him - each PHI serves in an area called his Range which is part of the large area under the $\mathrm{MOH}$.

The PHIs are specially involved in leprosy control in that they are expected to (a) maintain chartings and data regarding all leprosy patients in their areas, (b) visit defaulters and persuade them to resume treatment, (c) screen contacts of known patients, (d) assist in school and other leprosy surveys, (e) assist at leprosy clinics in their areas, and (f) notify any new cases to the Superintendent, Antileprosy Campaign (S/ALC).

Each PHI/ALC has patients in several $\mathrm{MOH}$ areas under his surveillance that is patients living in an area of between 1,000 and 2,000 square miles. $\mathrm{He}$ conducts the clinics in his area, and carries out leprosy surveys, defaulter retrieval and health education as best as he can manage. He is, however, unable to carry out leprosy control activities satisfactorily due to (a) the large area he has to cover, and (b) a reluctance on the part of general health staff to enter positively into leprosy control activities. This has resulted in nearly $50 \%$ of the known cases defaulting from regular treatment, which is available at 81 leprosy clinics held monthly, twice a month or weekly (depending on the numbers of 0305-7518/82/053193+02\$1.00 @ British Leprosy Relief Association 
cases scheduled to each clinic) in health institutions throughout the country. The only daily clinic is the Central Leprosy Clinic at Colombo General Hospital which is also the headquarters of the leprosy control programme, and conducted by a leprologist. Each patient is scheduled to the clinic of his choice, which often is not the closest to his residence, for reasons of stigma associated with the illness.

Most patients attend a leprosy clinic for the first time, after a period of treatment by Ayurvedic physicians ('herbalists'); more than 7,000 Ayurvedic Physicians are allowed by the government to practice in the villages and are expected thus to take part in PHC; regrettably, most of them know nothing about leprosy and their treatment often causes irreversible nerve damage and complications. Hence there is a conflict with regard to PHC between the western and indigenous systems of medicine in this country.

At present the government has taken steps to improve the PHC, especially of the rural population by increasing the number of PHMs so that each PHM serves a population group of 3,000 . PHMs are not only trained in midwifery and family planning, but also in detection of common noncommunicable diseases, including leprosy, and in directing the sufferers to the correct treatment centres. The' $y$ will work under the guidance and supervision of Medical Officers of Health who will also be part-time physicians in rural hospitals.

This scheme is designed to detect early illness and ensure speedy treatment by a referral system at the appropriate treatment centres, and thus prevent overcrowding at urban hospitals, with those who can be adequately treated at the peripheral institutions.

The health needs of Sri Lanka may be visualized from the following 17 areas of activity that have been identified for development of PHC: (1) Proper and adequate nutrition; (2) Safe water; (3) Basic Sanitation and Hygiene; (4) Maternal care; (5) Child care; (6) Family Planning; (7) Immunization; (8) Prevention and control of communicable diseases; (9) Prevention and control of non-communicable diseases; (10) Appropriate and early detection of common diseases and injuries; (11) Simple rehabilitation; (12) Health education; (13) Oral health; (14) Occupational health; (15) Mental health; (16) School health; (17) Prevention of blindness and visual impairment.

It will be seen that leprosy is concerned with activities in 8, 10,11 and 12 . Since 1970 we have been trying to emphasize these subjects in the teaching programmes of various members of the health staff and some of the prejudice against leprosy is being gradually overcome by lecture demonstration to paramedical workers during their pre-service and in-service courses. It must however be admitted that there are many difficulties and even conflicts within the health service itself, some of them relating to fear of this disease, which are still to be overcome. As far as leprosy is concerned, we do not as yet, in Sri Lanka, have a significant development of primary health in the sense of the WHO definition and a very great deal remains to be done in the field of health education and the regular systematic training of all members of our health service, including medical students and doctors. 